\title{
Integration of Probabilistic and Multi-Hazard Risk Assessment Within Urban Development Planning and Emergency Preparedness and Response: Application to Manizales, Colombia
}

\author{
Gabriel A. Bernal ${ }^{1} \cdot$ Mario A. Salgado-Gálvez $^{2} \cdot$ Daniela Zuloaga $^{1} \cdot$ \\ Julián Tristancho $^{3} \cdot$ Diana González $^{1} \cdot$ Omar-Darío Cardona $^{4}$
}

Published online: 6 September 2017

(C) The Author(s) 2017. This article is an open access publication

\begin{abstract}
The details of a multi-hazard and probabilistic risk assessment, developed for urban planning and emergency response activities in Manizales, Colombia, are presented in this article. This risk assessment effort was developed under the framework of an integral disaster risk management project whose goal was to connect risk reduction activities by using open access and state-of-theart risk models. A probabilistic approach was used for the analysis of seismic, landslide, and volcanic hazards to obtain stochastic event sets suitable for probabilistic loss estimation and to generate risk results in different metrics after aggregating in a rigorous way the losses associated to the different hazards. Detailed and high resolution exposure databases were used for the building stock and infrastructure of the city together with a set of vulnerability functions for each of the perils considered. The urban and territorial ordering plan of the city was updated for socioeconomic development and land use using the hazard and risk inputs and determinants, which cover not only the current urban area but also those adjacent areas where the expansion of Manizales is expected to occur. The emergency response capabilities of the city were improved by taking into account risk scenarios and after updating an
\end{abstract}

Mario A. Salgado-Gálvez

mario.sal.gal@gmail.com

INGENIAR Ltda, Bogotá D.C. 110221, Colombia

2 Centre Internacional de Metodes Numerics en Enginyeria (CIMNE), 08034 Barcelona, Spain

3 Universidad Distrital Francisco José de Caldas, Bogotá D.C. 110231, Colombia

4 Instituto de Estudios Ambientales (IDEA), Universidad Nacional de Colombia Sede Manizales, Manizales 170004, Colombia automatic and real-time post-earthquake damage assessment.

Keywords Emergency response $\cdot$ Manizales (Colombia) · Multi-hazard risk assessment · Probabilistic hazard analysis · Probabilistic risk assessment · Urban planning

\section{Introduction}

Manizales is the capital city of the Department of Caldas, located in the central Andean region of Colombia in an area with steep topographic conditions that produce very instable slopes. This condition facilitates the occurrence of landslides that can be triggered either by the occurrence of earthquakes or intense and prolonged rainfall. Within the urban area there are approximately 370,000 inhabitants and 113,000 buildings according to census and cadastral data (DANE 2005).

Since the 1980s the city has implemented an explicit integrated disaster risk management process. It has been based on a systemic institutional strategy that brings together scientific knowledge, promotes inter-institutional collaboration, and enhances overall community coping capacity. A recent ambitious disaster risk management program also was developed in Manizales, after an interinstitutional agreement was made between the Universidad Nacional de Colombia and the Autonomous Regional Corporation of Caldas (CORPOCALDAS), the regional environmental authority. The objective of joining interinstitutional efforts was to develop a set of projects that involve data management, research, monitoring, capacity building, and technological transfer. The goal of these integrated projects was to achieve "the improvement of the 
integral disaster risk management by strengthening the policies, strategies and instruments for risk understanding, risk reduction and disaster management, articulated to the development planning and the sustainable development" (Gestión del Riesgo - Manizales 2017).

The project was developed after taking into account the emergencies that occurred in the city in 2008 and 2011, which resulted in the closure of the main roads that provide access to the city, a significant number of lost lives, and a major disruption in the drinking water distribution services, among other impacts. Those crisis situations were the result of slope instability combined with the occurrence of extreme hydrometeorological events, which were a consequence of climate variability and change. Due to the vulnerability of the city to landslides, these events caused a significant social, economic, and environmental impact as well as widespread worry, without any precedent among inhabitants and local institutions, about future risk. This anxiety indicated the need for Manizales to have a better understanding of the overall vulnerability and risk conditions in the city and better programs by which to cope with future risk. The new program was financed by a temporary tax that was dedicated exclusively for disaster risk management activities (set equal to $0.5 \%$ of property value).

Tasks to be developed within the program were split into activities, and those related to risk knowledge aspects that are useful for urban planning and emergency response activities are summarized in this article. Within this risk knowledge cluster, it is important to highlight the update and harmonization of the city's seismic microzonation in order to comply with national requirements. Colombia's national earthquake resistant building code, NSR-10 (MAVDT 2010), mandates that every settlement with more than 100,000 inhabitants must have a seismic microzonation that is fully harmonized with the law's earthquake resistance specifications. Among the major requirements related to the harmonization process are the development of a detailed probabilistic seismic hazard analysis (PSHA), a regional seismicity study, geotechnical studies, and a comparison of the obtained design coefficients with those previously defined in the NSR-10 statute. Also, it is specified that those urban areas that already have a microzonation study, such as Manizales, need to harmonize that study with the requirements and functional shape of the elastic design spectra updated in 2010 by the Colombian Association for Earthquake Engineering (AIS).

Most of the tasks developed under the framework of this disaster risk management program are research activities instead of traditional consultancies, which required evaluation of the tasks (or their progress) during the execution phase while at the same time allowing space for enough flexibility to make adjustments at the execution stage.

\section{Probabilistic Analysis of Multiple Natural Hazards}

Manizales is located in an area prone to multiple hazards, where events associated with earthquakes, landslides, flash floods, and volcanic hazards can be expected. Therefore any comprehensive disaster risk assessment effort needs to take into account the contribution of the most relevant hazards and evaluate how these hazards interact with each other in order to have a complete overview of the catastrophe risk panorama. Within this project, a fully probabilistic approach was considered for the analyses of earthquakes, landslides, and volcanic eruptions, in order to be employed later in a fully probabilistic risk assessment, whose outputs would be useful to the development and planning of activities related to territorial ordering, landuse planning, and emergency response. A summary of the approach selected for the analysis of the different natural hazards is presented in Sect. 2.

\subsection{Probabilistic Seismic Hazard Analysis}

Seismic hazard, at bedrock level, was calculated using the latest version of the program CRISIS (Ordaz et al. 2013), a worldwide acknowledged and recognized tool for these assessments (Kalyan Kumar and Dodagoudar 2011; D'Amico et al. 2012), which corresponds to the seismic hazard assessment module of the CAPRA (Comprehensive Approach to Probabilistic Risk Assessment) Platform (Cardona et al. 2012; Marulanda et al. 2013). Most of the inputs used at this stage correspond to those used in the PSHA conducted for the definition of the seismic design coefficients for bridges in Colombia (Salgado-Gálvez et al. 2016a); the classical probabilistic approach, first proposed by Esteva (1967) and Cornell (1968), was followed. Local ground motion prediction equations (GMPEs) were used based on the study developed by Bernal (2014a) using a genetic algorithm framework. Data to develop the GMPEs was classified by tectonic environment and, as a result, two different sets of GMPEs were developed, one for intraplate and other subduction zone activity. Given the limited geographical extent of the Manizales area, it was assumed that, at bedrock level, there are not important spatial variations in seismic hazard levels and that values obtained at any location within the urban area are the same. The seismic design coefficients established in the NSR-10 are denoted as $A_{a}$ and $A_{v}$ and are related to the acceleration for peak ground acceleration (PGA) and $1.0 \mathrm{~s}$ respectively, both for a 475 year return period. The results obtained in this study for both parameters are equal to 0.20 and $0.21 \mathrm{~g}$, respectively. 


\subsection{Seismic Microzonation of Manizales}

The seismic microzonation of Manizales was updated by applying an innovative methodology for assessing site effects at a city level, as proposed by Bernal (2014a), which takes into account the geometry of the geological formations and several geotechnical characteristics of the soft soils. Based on a geological interpretation for the extension of the urban area of Manizales into the ruralurban transition zone, the elevation above the mean sea level of the geological contacts is defined and a 3D geometric model for the subsoil of the city is developed. The available geotechnical information is used to map the soil types into the geometric model. The static and dynamic characteristics of the soils are considered as random variables and their probability moments are calculated based on statistics from the available geotechnical data. A calculation grid, with a total of 1275 nodes, is defined along the urban area of the city and for each node a set of synthetic stratified soil columns are constructed with geotechnical parameters obtained by following their probability distributions. The dynamic soil response is calculated for each node of the grid by means of a 1D nonlinear analysis (lineal equivalent) based on a set of Fourier spectra generated at bedrock level that uses a source spectrum model for different combinations of moment magnitude and focal distances.

Synthetic stratified soil columns are generated by simulating the values of the geotechnical properties in depth. The stages to obtain a synthetic soil column are: (1) determine the total depth of the soil deposit according to the geological model; (2) divide soil depth into layers of the same thickness; (3) for each layer, determine the geotechnical properties by generating a random number that follows a probability distribution; and (4) the sequence of random numbers that defines the variation in depth of a geotechnical property in the simulated soil column is altered by the autocorrelation matrix of the property to obtain a correlated sequence.

By employing the same seismogenetic sources and seismicity parameters used to perform the PSHA at bedrock level and once having calculated the uncertainty associated to the dynamic soil response at each calculation point, it is possible to generate GMPEs that consider those uncertainties together with the amplification characteristics of each site. This permits performing a PSHA at each location with the objective of obtaining intensity exceedance rates for different ground motion levels and for different spectral ordinates.

To generate site-specific GMPEs, a calibrated source spectrum model is used, which provides the theoretical Fourier Amplitude Spectra (FAS) radiated from the seismogenetic sources. This model establishes the theoretical
FAS given a seismic moment and a focal distance. The theoretical FAS is then used to calculate the dynamic response of the soil column at a particular site and then determine the FAS at ground level. From this last result, by applying random vibrations theory, the spectral acceleration at ground level is obtained. This procedure is repeated for the complete magnitude and distance pairs that comprise the attenuation relationship at bedrock level so that the attenuation relationship is established for that site. Finally, for each considered fundamental period, an attenuation relationship and the calculated standard deviation are associated. The procedure is repeated for all the nodes of the calculation grid. These attenuation relationships are defined in terms of spectral accelerations for several fundamental periods. The site-specific GMPE's are generated by the Strong Motion Analyst computer program (Bernal 2012).

The PSHA is performed using the same methodology and computing program as that at bedrock level, but now considers the site-specific attenuation relationships. Seismic hazard is expressed in terms of exceedance rates for seismic intensities (spectral accelerations in this case) from where, if the same fixed values for the rates are chosen for the hazard curves at each calculation node, it is possible to obtain uniform seismic hazard maps at ground level, such as the one shown in Fig. 1 for $0.5 \mathrm{~s}$, and a return period of 475 years. More details about this study can be found in Bernal et al. (2015).

\subsection{Landslide Hazard}

Landslides are one of the most recurrent natural hazards in Manizales. Even though the expected losses associated with the occurrence of a single landslide are relatively small, when compared to those expected for hazards of larger consequences such as earthquakes, their high recurrence rate makes them of great importance when managing disaster risk at a regional or local level, since there can be an important accumulation of losses over time (Marulanda et al. 2008, 2010, 2011; Velásquez et al. 2014).

Landslide hazard analysis can be divided into two main components: (1) landslide susceptibility; and (2) triggering factors. The first component measures the probability of occurrence of a landslide at a given location, based on the intrinsic characteristics of the site such as slope, soil conditions, and vegetation coverage. It is a "static" measure of hazard, given the fact that it is computed using the current state of a site that has not necessarily yet slid. The second component is usually related to an external action that impacts the static conditions of the site, such as an earthquake or rainfall. Triggering factors are measured as the minimum required seismic acceleration or accumulated 
Fig. 1 Seismic hazard map of Manizales at ground level. $0.5 \mathrm{~s}$ and 475 years return period $(\mathrm{g})$



\subsubsection{Triggering Factors}

Triggering factors can be also defined in a probabilistic way that considers both spatial and temporal issues. Under this approach, triggering factors are considered to be external hazards that influence the occurrence of landslides at each site of analysis. The triggering hazards considered correspond to earthquakes and extreme rainfall, which are represented by stochastic event sets that provide the spatial distribution of the first two probability moments of the triggering intensity together with the annual occurrence frequency. Therefore each triggering event is not modeled using specific values but considers the geographical distribution of the probability density functions of the selected hazard intensities that are at the same time continuous probability distributions. Finally, a threshold intensity value must be defined, at each location of analysis, in order to establish the level of intensity that may cause landslides.

For all locations within Manizales, a rainfall threshold of $150 \mathrm{~mm}$ accumulated after 25 days of rain was defined (Londoño 2014a, b). This value was used in the stochastic rainfall scenarios developed by Bernal (2014b) to define the rain factor. In the case of earthquakes, the threshold corresponds to the maximum critical acceleration, $a_{c}$, which is a quantity that defines the seismic acceleration that is capable of causing a landslide in a slope. In this case, a spatial variation exists in the city for the threshold value at each location. In order to determine $a_{c}$, the methodology proposed by Newmark (1965) was used. Newmark's work models a landslide as a rigid and frictional block on an inclined plane in which the block has a $a_{c}$, which represents the threshold of acceleration required to exceed its shear resistance and detonate the landslide. A 
function of the static safety factor, $a_{c}$, and the geometry of the slope, can be expressed as:

$a_{c}=(F S-1) \sin \alpha$

where $F S$ is the static safety factor and $\alpha$ is the angle of the slope. Additional details of this procedure can be found in Bernal (2014b).

\subsubsection{Landslide Hazard Assessment}

Mathematically, the probability of occurrence of a landslide $\left(\operatorname{Pr}_{L}\right)$ at a particular site is given by,

$\operatorname{Pr}_{L}=\operatorname{Pr}_{S} \cdot \operatorname{Pr}\left(I>I_{T}\right)$

where $\operatorname{Pr}_{S}$ is the susceptibility of landslide occurrence and $\operatorname{Pr}\left(I>I_{T}\right)$ is the probability that the triggering intensity $I$ exceeds the threshold intensity $I_{T}$. Given that triggering hazards are modeled as a set of stochastic events, then the landslide probability of occurrence can be computed for each of those events, having each result in the same temporal probability or annual occurrence frequency as the triggering event. Therefore, a set of landslide hazard events is developed where each event has the same annual occurrence frequency as the triggering event, and is defined by the first two probability moments: mean and variance. Assuming a Bernoulli distribution, mean and variance are defined as:

Mean $=\operatorname{Pr}_{L}$

Variance $=\operatorname{Pr}_{L} \cdot\left(1-\operatorname{Pr}_{L}\right)$

The total hazard probability at a single location may be computed as the sum, for each landslide event, of the landslide probability, multiplied by the annual occurrence frequency of the event, $F_{i}$. This provides then an annual probability of landslide occurrence at each analysis location, which is also known as the annual occurrence rate $\left(v_{L}\right)$, expressed as:

$v_{L}=\sum_{i=1}^{N} \operatorname{Pr}_{L} \cdot F_{i}$

This provides a probabilistic representation of landslide hazard in terms of occurrence rates. Return periods may be computed at each site as the inverse of the annual occurrence rate. Figure 2 shows the hazard map of annual occurrence rate of rain-detonated landslides (top) and a segment of the hazard map used for urban planning, which takes into account five levels of hazard by lots as units of analysis (bottom), obtained for the city of Manizales. In practical terms, the top map panel shows how many times per year, on average, landslides occur at each location whereas the bottom map panel includes the translation of the probabilistic approach to levels of corrective and prospective interventions in the framework of urban planning.

\subsection{Volcanic Hazard}

Nevado del Ruiz is a broad, glacier-covered volcano located approximately $25 \mathrm{~km}$ southeast of Manizales. Melting of its summit icecap during historical eruptions, which date back to the sixteenth century, has resulted in devastating lahars of which the one that occurred in 1985, buried the city of Armero, and resulted in more than 20,000 fatalities may be the most remembered one. The main volcanic products associated with the activity of Nevado del Ruiz are: lahars, pyroclastic density currents (PDC), and ash fall. PDC is a highly destructive hazard that fortunately may only occur distant from the city, so there is virtually no chance that Manizales will be affected by this hazard (Bernal 2014c, see Fig. 3). In the case of ash fall, the probabilistic hazard assessment performed by Bernal (2014c) concluded that this particular hazard is not relevant for Manizales in terms of direct physical impact on the exposed structures and infrastructure of the city. In presenting the worst-case scenario, Fig. 3 shows the distribution of potential ash thickness after an explosive eruption of Nevado del Ruiz. The highest expected deposited ash thickness is, on average, around $1 \mathrm{~cm}$. In terms of physical damage, this scale of ash fall does not represent a critical condition in which house roofs may collapse. With regard to public health, there may be a relevant impact on the city and its inhabitants after an eruption of this scale, but the assessment of those consequences is out of the scope of this work. Finally, the current location and extent of the city has no exposure to lahar hazard. But the future urban expansion zone for Manizales, known as El Rosario, which is located $12 \mathrm{~km}$ southwest of the city, is susceptible to lahars. Therefore, lahar hazard was assessed, not to be used as input in the physical risk assessment, but as a land use conditioner for the future urban development of the city. This assessment was made by using the methodology proposed by Iverson et al. (1998), implemented in the computer program Volcanic Hazard Analysis and Simulation Tool (VHAST) (Bernal 2010). This model considers that topography has a fundamental role in the final location of the volume of the material transported by a lahar. The final extent of the deposit of this lava-rock-mud material depends only on the relationship between the general slope of the volcano, the cross sections of the transit channel, and the breadth of the flood plain. Figure 3 shows the lahar hazard map for the Chinchiná River, and a zoom over the urban expansion area of El Rosario. In summary, probabilistic volcanic hazard considers all the ways in which the volcano can erupt, meaning that all possible outcomes are included in the resulting hazard maps. This provides a 
Fig. 2 Top Rain triggered landslide hazard map (annual exceedance rate); Bottom Map of levels of intervention by lots for urban planning of Manizales based on the level of hazard and risk (very low, low, moderate, high, and very high). Source Londoño (2014a, b)
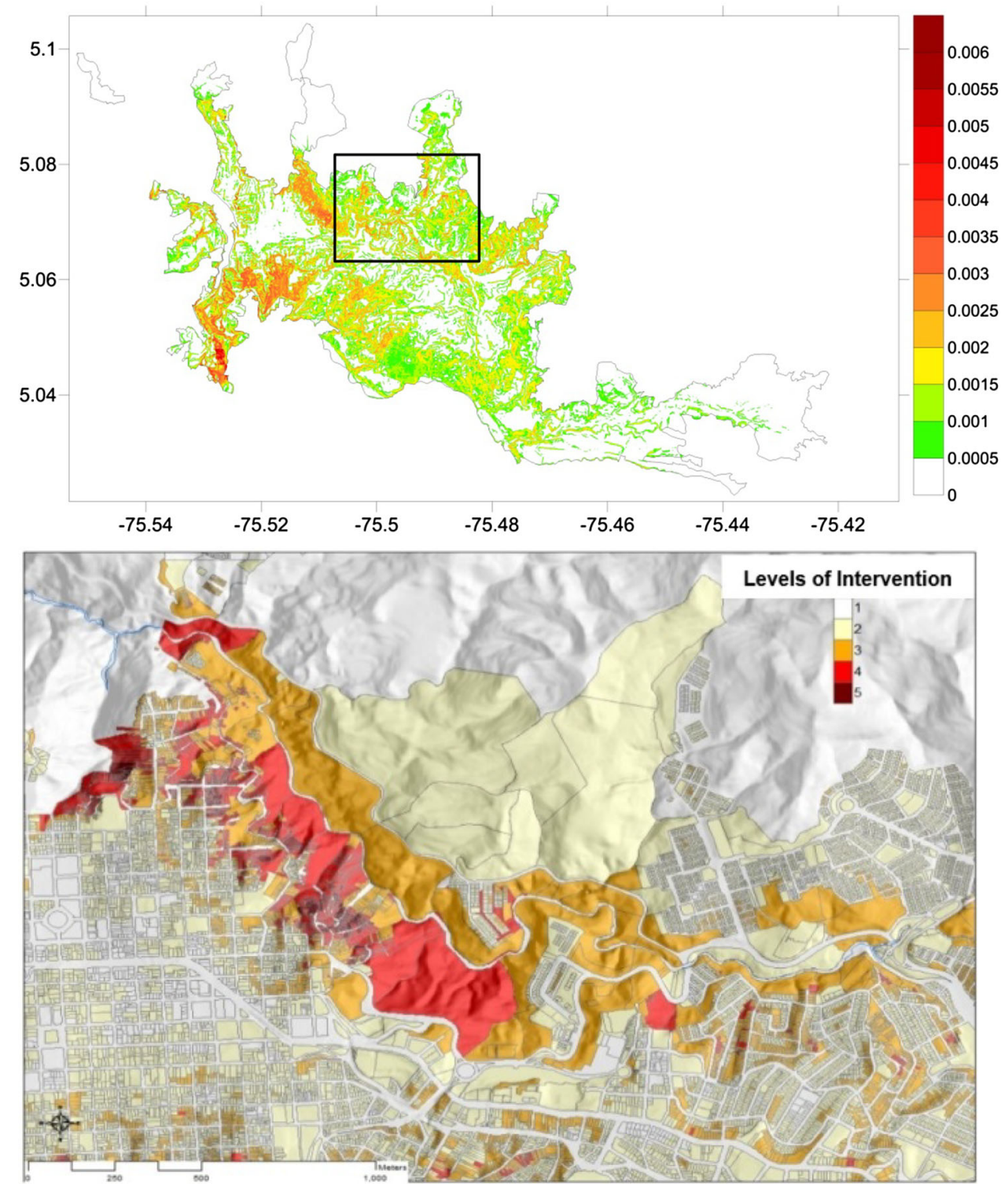

representation of volcanic hazard that accounts for both spatial and temporal probabilities that a particular location is affected by volcanic products, at any moment in the future. This type of assessment is very useful for land-use and urban planning, as well as for evacuation purposes during the development of an eruptive process detected by the Volcano Observatory of Manizales.

\section{Probabilistic Risk Assessment}

State-of-the-art and fully probabilistic risk assessments require specific representations for their different components (mainly for hazard and vulnerability) in order to not only obtain the feasible scope of future losses but also to rigorously account for and propagate the uncertainties associated with any losses throughout the analysis process. In that sense, the required output for the probabilistic hazard analyses generated for any of the considered perils is a set of stochastic events that have to comply with different requirements, such as being collectively exhaustive, mutually exclusive, have an associated occurrence frequency and provide, at least, for each of the hazard intensities, the first two probability moments. But in the case of physical vulnerability, although it is acknowledged that different representations of this dimension allow a probabilistic representation (for example, damage probability matrixes and fragility curves), the one known as the vulnerability function is far more useful. This function provides a continuous, quantitative, and probabilistic relationship between different hazard intensities (for example, spectral acceleration, water depth, and ash fall thickness) 

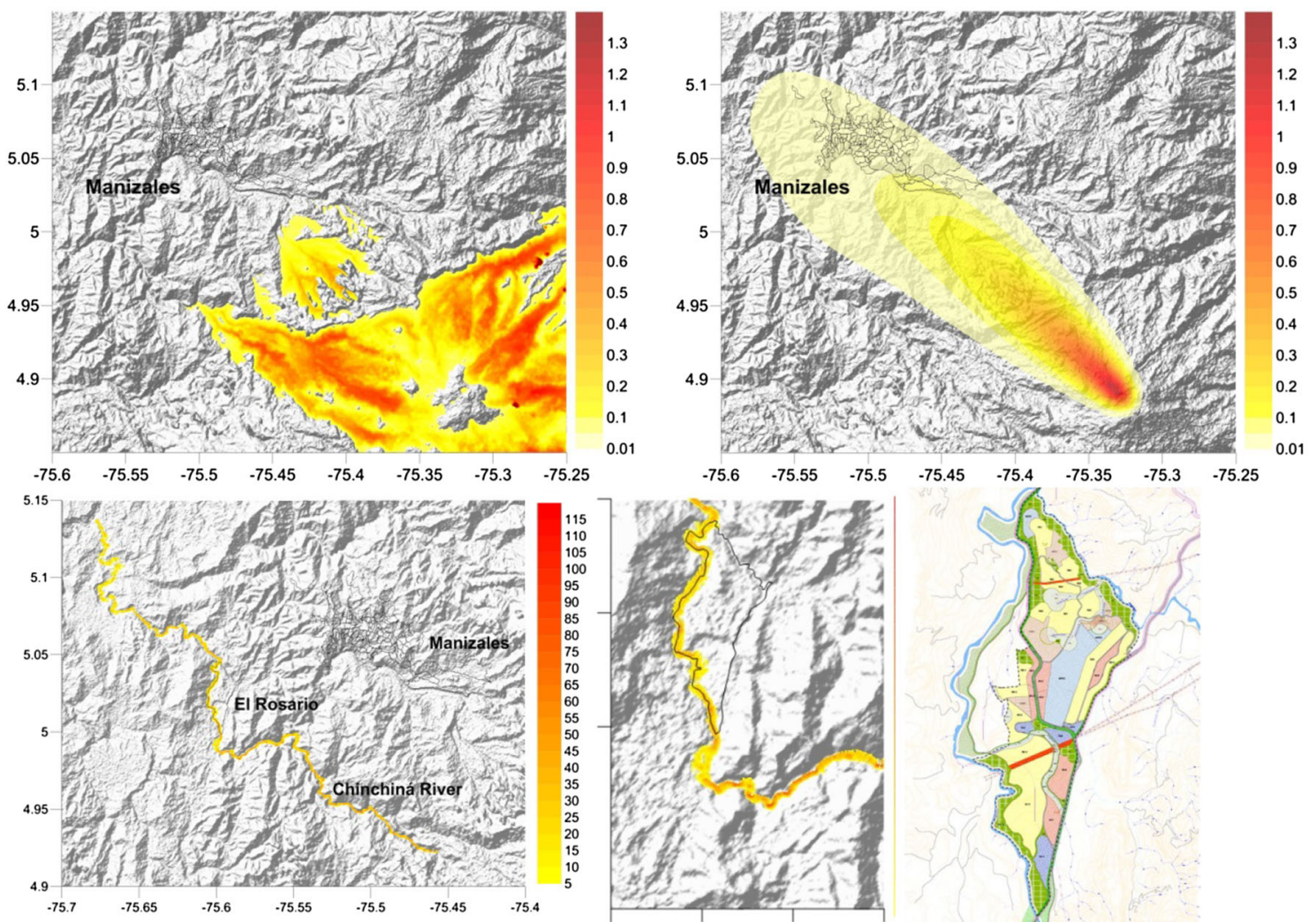

Fig. 3 Top left PDC dynamic pressure hazard map (in Pascals). Top right Ash fall thickness for the worst-case scenario eruption of Nevado del Ruiz (in meters). Bottom left Lahar hazard inundation

map of the Chinchiná River (in meters). Bottom center Zoom to the El Rosario expansion area of Manizales. Bottom right Lineal parks and land-use planning of El Rosario. Source Bernal (2014c)

with the mean damage ratio (MDR). This last variable corresponds to the ratio, in monetary terms, of the damage cost associated with certain hazard intensity against the total exposed value of each asset under analysis.

Complete details about the methodological framework used for the estimation of losses associated with natural hazards can be found in Ordaz (2000) and Salgado-Gálvez et al. (2014). For each of the events included in the event sets produced for every hazard considered, a convolution between its intensities and vulnerability functions is performed in order to obtain the expected losses on each asset considered (in this case the public and private buildings of Manizales). After this process is completed, the estimation of exceedance rates for different loss values is performed and, with those values available, what is known as the loss exceedance curve (LEC) is obtained. When assessing catastrophe risk linked to hazards with different origins, which in some cases may be related, a robust and rigorous aggregation framework for the losses is required. Among them, the one proposed by Ordaz (2014) has proven to be appropriate for most of the cases since it is fully compatible with the Poissonian assumptions widely used for the estimation of loss exceedance rates in catastrophe risk models.
The loss for a given event is therefore evaluated by considering that the hazards, which belong to the same temporality, occur simultaneously. There is no simple or unambiguous way to evaluate losses when several hazards occur simultaneously. For the purposes of this project, the following expression has been used to evaluate the loss of each of the exposed assets, which corresponds to a cascade damage model, where the order of exposure of different intensities is irrelevant since a multiplicative process is assumed to occur:

$L_{i}=\prod_{j=1}^{M}\left(1-L_{i j}\right)$

where $L_{i}$ is the loss associated to the $i$ th event, $L_{i j}$ is the loss associated to the $i$ th event due to the occurrence of the $j$ th hazard, and $M$ is the number of simultaneous hazards considered in the timeframe to which the $i$ th event belongs. It is important also to highlight that the values of $L_{i j}$ are considered to be random variables, and as a result, $L i$ is therefore also a random variable. If the distribution of probability of $L_{i j}$ is known, however, and reasonable assumptions are made as to their level of correlation (that they are perfectly correlated, for example), the moments of 
the probability distribution of $L_{i}$ can be determined using Eq. 6.

\subsection{Input Data}

The development of a fully probabilistic risk assessment requires the development of input data linked to (at least) four different categories, which are hazard, exposure, vulnerability, and loss. For natural hazards, a specific stochastic event set was developed for each hazard to comply with the previously explained requirements that mandate suitability for use under a fully probabilistic loss assessment framework. For exposure, a complete database that includes all public and private buildings of Manizales, with more than 110,000 entries, was assembled using official cadastral and census data. For each building, a complete characterization process was developed in order to assign to each of the entries in the database relevant data such as construction material, structural system, number of stories, age, replacement cost, and number of occupants, among other variables. Those exposure characteristics allowed the association of a unique vulnerability function for each of the hazards considered to each of the entries in the exposure database in order to obtain the expected damages and losses. Those vulnerability functions were developed using different approaches that range from experimental models, used mainly for the historical buildings made from earthen materials, to analytical models used mostly for flexible structures such as medium and high-rise reinforced concrete buildings. For the loss assessment, the CAPRA-GIS program (ERN-AL 2011) was used. This program incorporates the methodologies developed by Ordaz $(2000,2014)$, which have been acknowledged to be suitable tools to perform risk assessments at different scales (Cardona et al. 2013, 2014, 2015; Marulanda et al. 2013; Salgado-Gálvez et al. 2016b, c).

\subsection{Results}

Risk results are presented in terms of the average annual loss (AAL) and the probable maximum loss (PML), which are probabilistic risk metrics commonly used in actuarial mathematics. A detailed definition of these metrics can be found in Ordaz (2000), Marulanda (2013), and Bernal (2014a).

The losses caused by earthquakes, including detonated landslides and by rain triggered landslides, are shown in Table 1. The risk metrics are included both in absolute and relative terms; the first refer to monetary values whereas the second note the ratio between the expected loss and the total exposed value of the city. Relative AAL's are usually expressed as an amount per thousand (\%o).

The AAL and the PML may also be evaluated for portfolios of public and private buildings (for example, schools, hospitals), bridges, pipelines, and so on. They are very useful to define a strategy of risk transfer and retention by sectors and for different stakeholders of the city. Marulanda et al. (2014, 2016) and Salgado-Gálvez et al. (2017a, b) describe the evaluation and use of these probabilistic metrics to design and implement insurance policies in Manizales. The AAL is the best indicator of physical risk, not only for insurance but also for other risk reduction actions such as socioeconomic development planning, territorial ordering and urban planning, emergency response, and cost-benefit analysis of retrofitting and mitigation works. Carreño et al. (2017) describe the use of probabilistic risk results by districts in Manizales for the holistic evaluation of risk (Cardona 2004, 2011) and the formulation of the city's disaster risk management plan (Cardona et al. 2016a).

\section{Considering Risk in Urban Planning}

Natural hazards and risk should be considered as a determinant in the land-use planning of cities and hydrological basins, in accordance with the Law 9 of 1989 and Law 388 of 1997 (Congreso de Colombia 1989, 1997) that includes the legislation on urban planning and territorial development, among others. The city administration of Manizales has used multi-hazard risk assessment to include hazards and risk information in its Territorial Ordering Plan (Manizales 2017), which is approved for the following 12 years. In case of land that is classified as containing a nonreducible risk situation, the land should be defined as a land of protection, that is any permanent urban activity in that place should be avoided. The definition of nonreducible risk depends on the cost-benefit analysis of the cost of work required to reduce the level of hazard and risk. Risk can be configured (when the area is urbanized) or implicit (when the area is not yet urbanized). Figure 4 shows the flowchart of the steps needed not only to define the classification of land (as protected land or not) but also the type of required interventions depending on whether the area is occupied or not. The area can be classified temporally as an area of conditional development until detailed studies are done (using the specific geotechnical norm of Manizales) as part of a programmatic component of the city plan. In this fashion, development can be differentiated over time based on a principle of gradualness that is specific to the local context.

It is important to highlight that seismic microzonation is mainly prescriptive (that is, useful for the definition of the construction requirements for buildings and other infrastructure) and seismic losses depend on the vulnerability of the exposed structural elements. It would be useful to define the liquefaction potential in the areas of analysis. From a planning perspective, landslides triggered by rain or by earthquakes, volcanic lahars, and flash floods pose a 
Table 1 Summary of risk results for Manizales

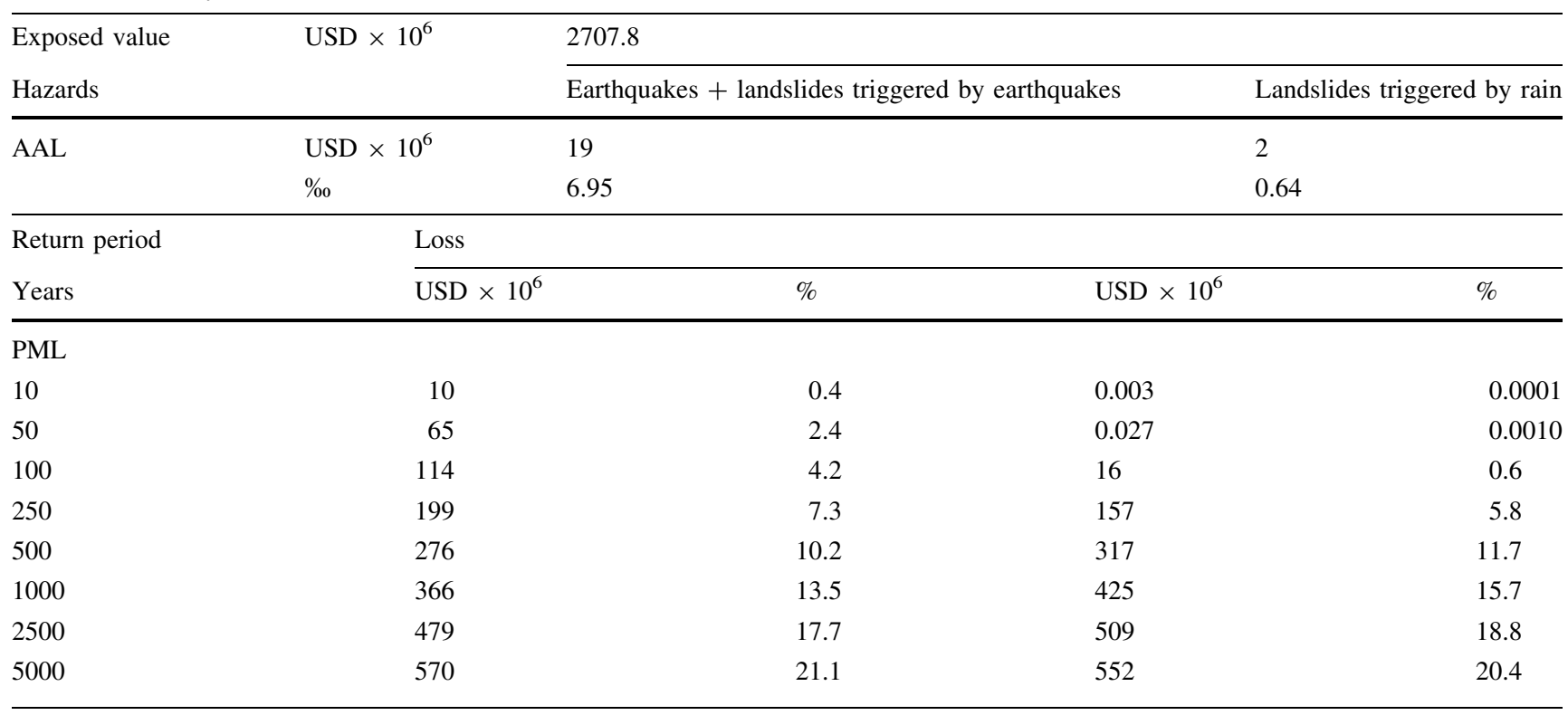

$1 \mathrm{USD}=2900$ Colombian pesos $(\mathrm{COP})$. Exchange rate as per 4 January 2017

threat of sufficient severity to define the level of risk (configured or implicit) at the highest level, because in most cases vulnerability already is at its maximum. In this approach it is not so relevant to define, as in many other cases, areas of high, medium, and low hazard or risk, but rather to identify levels of intervention based on the probability level of events and their effects - the expected annual occurrence of events and the expected annual loss.

Table 2 illustrates an example of the levels of intervention based on the levels of hazard and risk from very low to very high (configured or implicit depending on the area is occupied or not by buildings or infrastructure). These interventions mean the actions and investments to be conducted in each identified area. Three intervention classes are considered: prospective (when the area is not occupied), corrective (when the area is occupied), and prescriptive (regarding the suggested requirements to reduce or avoid the hazard and risk increasing). More relevant than defining the level of hazard and risk is defining the type of interventions to be conducted by the territorial ordering and land-use plan of the city. It includes the interventions and actions such as protection works, early warning systems, resettlement of dwellings, and restriction of land use, among others.

\section{Considering Risk in Emergency Response Planning}

In 2003, Manizales implemented an emergency response plan (Manizales 2016a) that was updated in 2016 as the municipal strategy for emergency response (Manizales 2016b), following also the requirements of Law 1523 of 2012 (Congreso de Colombia 2012). The new version of this plan, enacted by the city's decree 416 of 2016, considers different hazard events, such as moderate and strong earthquakes, volcanic eruptions, floods, and landslides triggered by quakes and rain, that have been analyzed through the Table 2 multi-hazard risk assessment mechanism and that define the city's preparedness and the interagency ability to respond in case of disaster (Cardona et al. 2016b).

In addition, one of the activities that benefitted the most after performing a multi-hazard risk assessment was the systematization and expansion of the laboratory of automatic seismic instrumentation (LISA). In particular, this facility improved by tuning up an accelerographic network when more maintenance and repair was provided to the existing stations (located at ground level), while at the same time putting into service five new stations, which were acquired within the budget of the project. One of the new sites was located at $45 \mathrm{~m}$ depth (in a borehole at bedrock level) and developed and implemented data communication and transmission systems in real time. After this expansion, Manizales has 12 fully instrumented locations, completely interconnected and synchronized, which simultaneously make use of the same specific 
Fig. 4 Flowchart of the land classification definition and type of required interventions

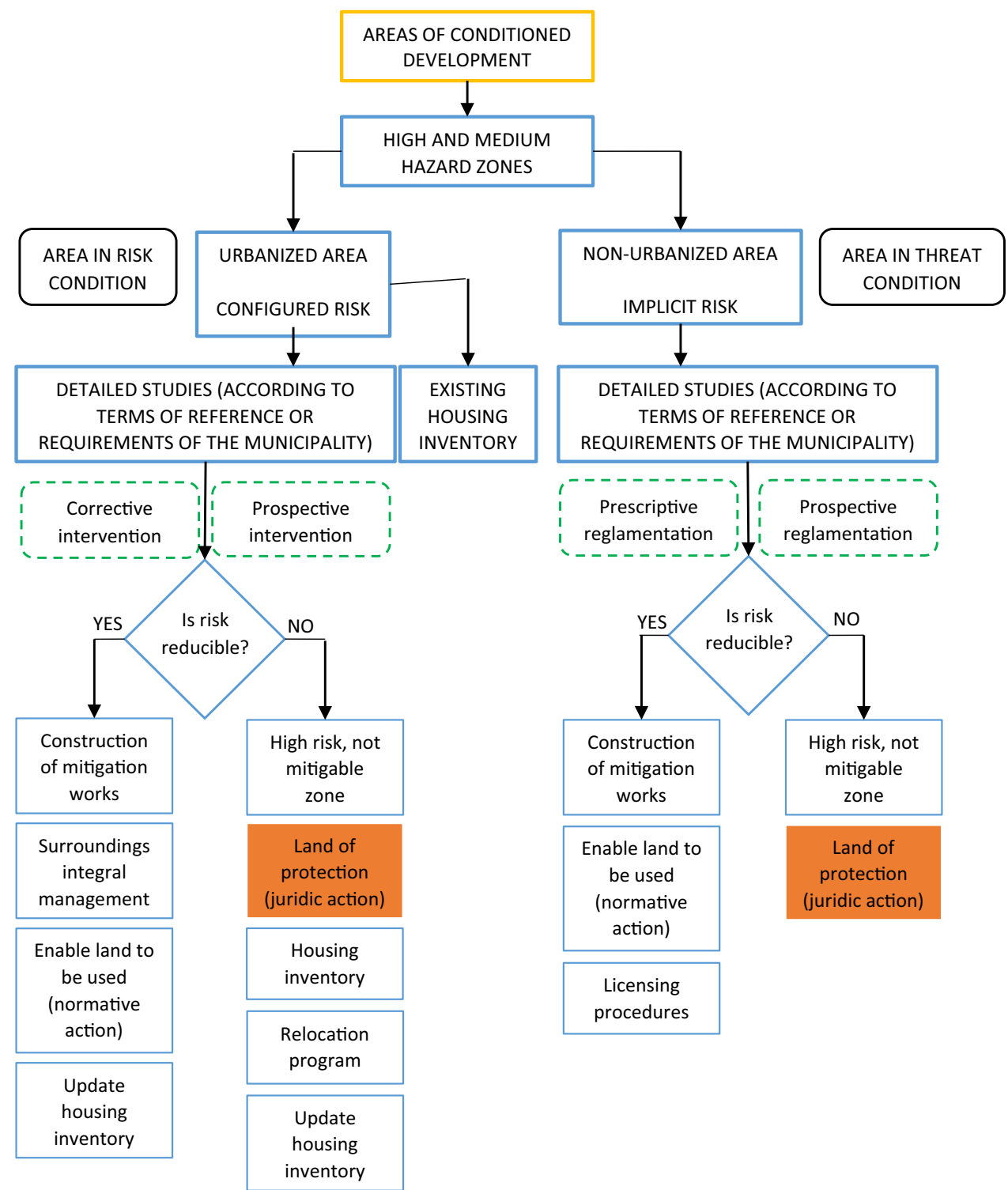

Table 2 Interventions to be done in areas at risk, according to the urban planning laws of Manizales. Source Adapted from Lavell et al. (2016)

\begin{tabular}{|c|c|c|c|c|}
\hline $\begin{array}{l}\text { Intervention } \\
\text { level }\end{array}$ & $\begin{array}{l}\text { Risk (implicit or } \\
\text { configured) }\end{array}$ & $\begin{array}{l}\text { Prospective intervention (non- } \\
\text { occupied) }\end{array}$ & $\begin{array}{l}\text { Corrective intervention (occupied } \\
\text { area) }\end{array}$ & $\begin{array}{l}\text { Prescriptive interventions } \\
\text { (requirements) }\end{array}$ \\
\hline 5 & $\begin{array}{l}\text { Highly probable } \\
\text { affect }\end{array}$ & $\begin{array}{l}\text { Total prohibition of structures and } \\
\text { population }\end{array}$ & Resettlement & Explore how to reduce hazards \\
\hline 4 & Feasible affect & $\begin{array}{l}\text { Hazard reduction works }+ \text { early } \\
\text { warning systems }\end{array}$ & $\begin{array}{l}\text { Reduction and protection } \\
\text { works }+ \text { early warning }\end{array}$ & $\begin{array}{l}\text { Reduce hazard and protect the } \\
\text { area }\end{array}$ \\
\hline 3 & Improbable affect & Hazard control works & Reduction and protection works & $\begin{array}{l}\text { Control the hazard and protect } \\
\text { areas }\end{array}$ \\
\hline 2 & Remote affect & Hazard control works & Impede growth of hazards & $\begin{array}{l}\text { Control the hazard and monitor } \\
\text { its development }\end{array}$ \\
\hline 1 & $\begin{array}{l}\text { Very improbable } \\
\text { affect }\end{array}$ & Control on increase in hazards & Impede growth of hazards & Verify no increase in hazards \\
\hline
\end{tabular}


Fig. 5 General overview of the process followed to assess postearthquake damage

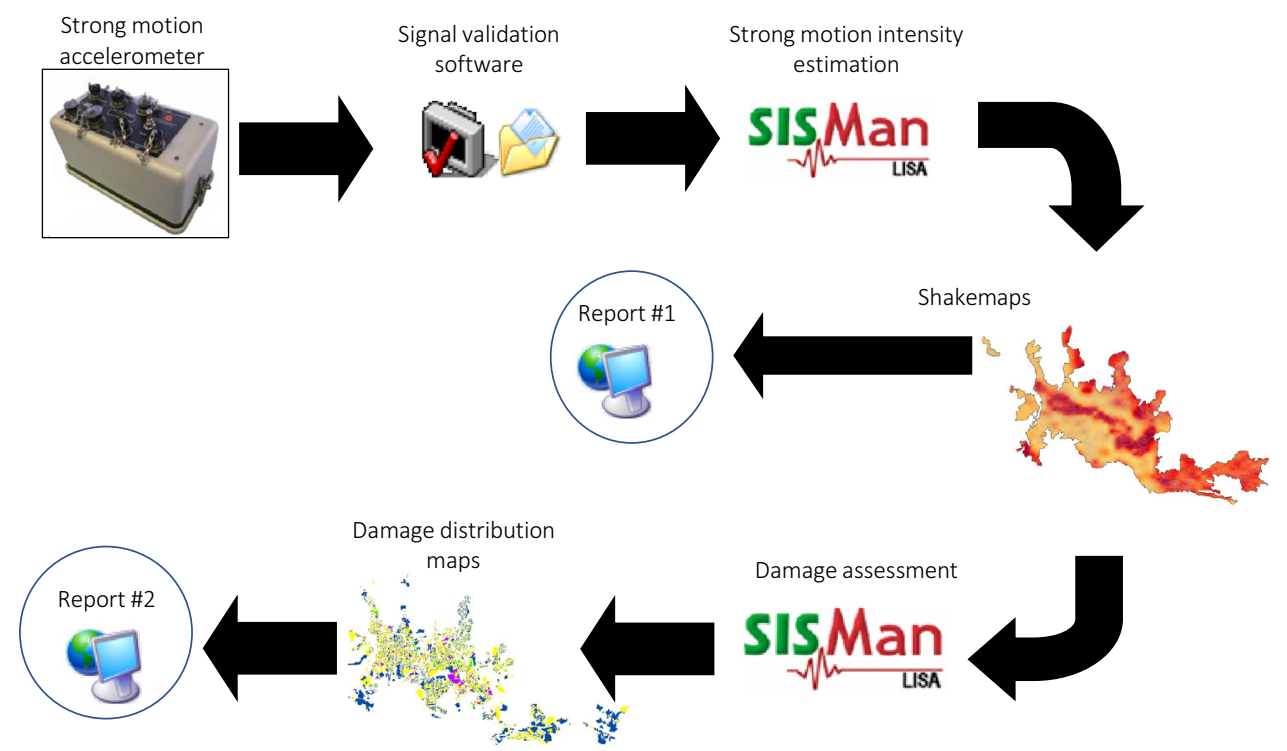

software, developed for the system's management as well as data reading, processing, and transmission.

Within this task, different activities were performed. These efforts included the diagnosis of existing equipment, the corrective maintenance of accelerograph stations, and the design and construction of the sheds where new equipment was installed. The seismic information system of Manizales (SISMan-LISA) was updated. This strengthens a tool that contributes to the city's seismic risk management in activities related to preparedness and emergency response, since it provides relevant input data for the proper operation and assignment of physical and human resources within the city during a crisis situation.

The system has a central accelerograph station, located at bedrock level, in which the ground motion is recorded after the occurrence of any earthquake. The signal is sent using telemetric procedures to the central calculation system in order to perform a validation process to determine whether or not the ground motion corresponds to a seismic event. If the signal is validated, the dynamic 1D response of the soils in Manizales is modelled by using the synthetic soil strata data obtained during the update and harmonization process of the seismic microzonation of the city. As a result of this procedure, a complete accelerogram, at ground level, is obtained at each of the 1275 nodes of the urban grid. From these accelerograms, the ground motion intensities for the entire city are obtained for a wide range of spectral ordinates in terms of accelerations. With these data available, the estimation of damage is performed on each of the public and private buildings and water lifelines of the city. An estimate of building collapse and water delivery/supply interruption probability is generated as well as the probable number of fatalities and injured. The result is reported, in a matter of minutes, in terms of maps and general statistics, to a list of email accounts and telephone numbers of users who have responsibility for emergency response and to whom specific access permission has been granted. Figure 5 shows a general overview of the steps followed for post-earthquake damage assessment. The complete process, from the recording of the strong motion to the sending of the damage reports, takes $<3$ min. Damage reports are sent only to specific individuals with high responsibility profiles in the emergency response.

During this process a probabilistic estimation of damages, losses, and casualties is created by having a predefined exposure database (for the public and private buildings and water lifelines of Manizales) and their associated vulnerability models. But instead of reading the hazard information from a previously developed stochastic event set, the real data recorded by the city's accelerograph network are matched with vulnerability data on the dynamic response of the underlying soils within the urban area of Manizales to account for the impact level of a real hazard. This information is also supplemented with other tools (for example, an app for smartphones) for postearthquake damage evaluation. This app was developed within the framework of a native application for Android smartphones for the evaluation of building damage after an earthquake program in order to improve evaluation of the habitability and reparability of buildings after an earthquake using an expert system of computational intelligence (Carreño et al. 2007, 2010, 2015a, b; Velasquez 2015). 


\section{Conclusions}

Disaster risk must be evaluated following a multi-hazard approach. Assessments of individual hazards are useful but not exhaustive, and leave a knowledge gap that will lead to management actions that are biased and partial. The most appropriate way to perform multi-hazard risk assessments is to follow a probabilistic approach in which not only the uncertainties in the definition and calculation of hazard, exposure, and vulnerability are rationally involved, but also a mathematical framework is provided to combine in one framework all the losses caused by different hazards, either dependent (for example, rainfall and landslides) or independent (for example, rainfall and volcanic eruptions).

Planning instruments at the city level need appropriate inputs from disaster risk assessment techniques and from research methods that provide useful responses to the real questions that arise from urban planning, development planning, risk management planning, and emergency response planning. In the case of urban planning, for example, it is necessary to provide insights better regarding to what to do than if the risk is high, medium, or low.

A fully probabilistic multi-hazard risk model was applied, for the first time, in Manizales, Colombia, as part of an ambitious disaster risk assessment and management program. The risk evaluations presented in this article can be useful, not only to quantify the risk associated with different perils, but to define concrete actions towards the management and reduction of these risk. Having the same knowledge base for all management activities allows the city to constantly enhance its existing models of hazard, exposure, and vulnerability, and to update risk evaluations and provide feedback on the management actions contemplated and/or implemented.

Acknowledgements This work was carried out within the framework of the inter-institutional agreement between the Universidad Nacional de Colombia, Manizales Campus, and the Corporación Autónoma Regional de Caldas (CORPOCALDAS) - the regional environmental authority - and the authors are grateful for the unwavering support and encouragement provided by the leaders and staff of both institutions.

Open Access This article is distributed under the terms of the Creative Commons Attribution 4.0 International License (http://crea tivecommons.org/licenses/by/4.0/), which permits unrestricted use, distribution, and reproduction in any medium, provided you give appropriate credit to the original author(s) and the source, provide a link to the Creative Commons license, and indicate if changes were made.

\section{References}

Bernal, G.A. 2010. Volcanic Hazard Analysis and Simulation Tool (VHAST). Computer program for probabilistic volcanic hazard modelling. http://www.vhast.org/. Accessed 26 Nov 2016.
Bernal, G.A. 2012. Strong motion analyst. Computer program for processing strong motion and seismological data.

Bernal, G.A. 2014a. Methodology for the modelling, calculation and calibration of seismic hazard parameters to assess risk in a probabilistic way (Metodología para la modelación, cálculo y calibración de parámetros de la amenaza sísmica para la evaluación probabilista del riesgo). Doctoral thesis. Universidad Politécnica de Cataluña, Barcelona, Spain (in Spanish).

Bernal, G.A. 2014b. Multi-hazard modelling of disaster risk in Manizales (Modelación multiamenaza del riesgo de desastes en Manizales). Technical report. Gestión del Riesgo-Manizales. Corporación Autónoma Regional de Caldas (CORPOCALDAS) 2014 (in Spanish).

Bernal, G.A. 2014c. Use of a volcanic hazard evaluation technique, compatible with CAPRA, based on the information available for Manizales (Utilización de la técnica de evaluación de la amenaza volcánica, con enfoque tipo CAPRA, con base en la información disponible para Manizales). Technical report. Gestión del Riesgo-Manizales. Corporación Autónoma Regional de Caldas (CORPOCALDAS) 2014 (in Spanish).

Bernal, G.A., O.D. Cardona, M.A. Salgado-Gálvez, and C. Villegas. 2015. Update of the seismic microzonation of Manizales (Actualización de la microzonificación sísmica de Manizales). Proceedings of the VII National Congress on Earthquake Engineering, Bogotá D.C., Colombia (in Spanish).

Cardona, O.D. 2004. The need for rethinking the concepts of vulnerability and risk from a holistic perspective: A necessary review and criticism for effective risk management. In Mapping vulnerability: Disasters, development and people, ed. G. Bankoff, G. Frerks, and D. Hilhorst, 37-51. London: Earthscan Publishers.

Cardona, O.D. 2011. Disaster risk and vulnerability: Concepts and measurement of human and environmental insecurity. In Coping with global environmental change, disasters and securitythreats, challenges, vulnerabilities and risks, ed. H.G. Brauch, U. Oswald Spring, C. Mesjasz, J. Grin, P. Kameri-Mbote, B. Chourou, P. Dunay, J. Birkmann, 107-121. Berlin and New York: Springer-Verlag.

Cardona, O.D., G.A. Bernal, M.G. Ordaz, M.A. Salgado-Gálvez, S.K. Singh, M.G. Mora, and C.P. Villegas. 2015. Update on the probabilistic modelling of natural risks at global level: Global risk model - global earthquake and tropical cyclone hazard assessment. Disaster risk assessment at country level for earthquakes, tropical cyclones (wind and storm surge), floods, tsunami and volcanic eruptions. CIMNE \& INGENIAR Consortium, Barcelona \& Bogotá.

Cardona, O.D., G.A. Bernal, M.G. Ordaz, M.A. Salgado-Gálvez, S.K. Singh, M.G. Mora, L.E. Yamín, and A.H. Barbat. 2013. Probabilistic modelling of natural risks at the global level: Global risk model. Global earthquake and cyclone models and Disaster risk assessment of countries for seismic, cyclone and flood hazards. Consortium CIMNE, INGENIAR, ITEC, EAI, Barcelona-Bogotá. http://www.preventionweb.net/english/ hyogo/gar/2013/en/bgdocs/CIMNE\%20ET\%20AL\%20Global\% 20Risk\%20Model\%20GAR-2013_Tables\%20ENGr\%20v2.pdf. Accessed 6 Jan 2017.

Cardona, O.D., M.G. Ordaz, M.G. Mora, M.A. Salgado-Gálvez, G.A. Bernal, D. Zuloaga-Romero, M.C. Marulanda, L. Yamín, and D. González. 2014. Global risk assessment: A fully probabilistic seismic and tropical cyclone wind risk assessment. International Journal of Disaster Risk Reduction 10(B): 461-476.

Cardona, O.D., M. Ordaz, E. Reinoso, L.E. Yamín, and A.H. Barbat. 2012. CAPRA-Comprehensive approach to probabilistic risk assessment: International initiative for risk management effectiveness. Proceedings of the 15th world conference on earthquake engineering, 24-28 September 2012, Lisbon, Portugal. 
Cardona, O.D., M.P Perez, and D.C. Suarez. 2016a. Municipal plan for disaster risk management of Manizales. (Plan Municipal de Gestión del Riesgo de Desastres de Manizales). INGENIAR 2016 (in Spanish).

Cardona, O.D., M.P Perez, and D.C. Suarez. 2016b. Municipal strategy for emergency response of Manizales. (Estrategia Municipal de Respuesta a Emergencias de Manizales). INGENIAR 2016 (in Spanish).

Carreño, M.L. 2015a. Expert system for the evaluation of building habitability and reparability after an earthquake. Theoretical base and algorithm. (Sistema experto para evaluar la habitabilidad y reparabilidad en edificios después de un sismo. Base teorica y algoritmo). Technical report. Gestión del RiesgoManizales. CORPOCALDAS 2015 (in Spanish).

Carreño, M.L. 2015b. Field manual for building inspection after an earthquake. (Manual de campo para la inspección de edificaciones después de un sismo). Technical report. Gestión del Riesgo-Manizales. CORPOCALDAS 2015 (in Spanish).

Carreño, M.L., O.D. Cardona, and A.H. Barbat. 2007. Neuro-fuzzy assessment of building damage and safety after an earthquake. In Intelligent computational paradigms in earthquake engineering, ed. N.D. Lagaros, and Y. Tsompanakis, 123-157. Hershey, PA: Idea Group Publishing.

Carreño M.L., O.D. Cardona, and A.H. Barbat. 2010. Computational tool for post-earthquake evaluation of damage in buildings. Earthquake Spectra 26(1): 63-86.

Carreño, M.L., O.D. Cardona, A.H. Barbat, D.C. Suarez, M.P. Perez, and L. Narvaez. 2017. Holistic disaster risk evaluation for the urban risk management plan of Manizales, Colombia. International Journal of Disaster Risk Science 8(3). doi:10.1007/ s13753-017-0136-7.

Congreso de Colombia. 1989. Law 9 of 1989. http://www.alcaldiabo gota.gov.co/sisjur/normas/Norma1.jsp?i=1175. Accessed 26 Nov 2016 (in Spanish).

Congreso de Colombia. 1997. Law 388 of 1997. http://www. alcaldiabogota.gov.co/sisjur/normas/Norma1.jsp?i=339. Accessed 26 Nov 2016 (in Spanish).

Congreso de Colombia. 2012. Law 1523 of 2012. http://www. alcaldiabogota.gov.co/sisjur/normas/Norma1.jsp?i=47141. Accessed 26 Nov 2016 (in Spanish).

Cornell, C.A. 1968. Engineering seismic risk analysis. Bulletin of the Seismological Society of America 58(5): 1583-1606.

D'Amico, V., C. Melleti, and F. Martinelli. 2012. Probabilistic seismic hazard assessment in the high-risk area of south-eastern Sicily (Italy). Bollettino di Geofisica Teoria ed Applicata 53(1): 19-36.

DANE (Departamento Administrativo Nacional de Estadística). 2005. Results and projections (2005-2020) of the 2005 census (Resultados y proyecciones (2005-2020) del censo 2005). http://www.dane.gov.co/files/censo2005/PERFIL_PDF_ CG2005/17001T7T000.PDF. Accessed 6 Oct 2016 (in Spanish).

ERN-AL (Evaluación de Riesgos Naturales América Latina). 2011. CAPRA-GIS v2.0. Program for probabilistic risk assessment. Bogotá D.C., Colombia.

Esteva, L. 1967. Criteria for the definition of seismic design spectra (Criterios para la construcción de espectros de diseño sísmico). Proceedings of the 3rd Pan-American Symposium of Structures, 3-8 July 1967, Caracas, Venezuela (in Spanish).

Gestión del Riesgo - Manizales. 2017. Risk management project (Proyecto GR Manizales). http://www.gestiondelriesgomani zales.com/index.php?option $=$ com_content\&view $=$ article\&id $=$ 124\&Itemid=228. Accessed 14 Jan 2016 (in Spanish).

Iverson, R.M., S.P. Schilling, and J.W. Vallance. 1998. Objective delineation of lahar-inundation hazard zones. The Geological Society of America Bulletin 110(8): 972-984.
Kalyan Kumar, G. and G.R. Dodagoudar. 2011. Seismic input motion for Kanchipuram, South India. International Journal of Earth Sciences and Engineering 4: 189-192.

Lavell, A., E. Mansilla, A. Chavez, O.D. Cardona, M.P. Perez. 2016. Decision, implementation and social and economic impacts of climate risk induced resettlement in urban areas: A final regional report for Latin America. The Bartlett Development Planning Unit. University College London. United Kingdom.

Londoño, J.P. 2014a. Evaluation of susceptibility to landslides in the city of Manizales (Evaluación de la susceptibilidad a los deslizamientos en la ciudad de Manizales). Technical report. Gestión del Riesgo-Manizales. CORPOCALDAS 2014 (in Spanish).

Londoño, J.P. 2014b. Landslides susceptibility, hazard zoning and triggering rain thresholds. (Zonificación de susceptibilidad y amenaza por deslizamientos y umbrales de lluvia detonante). Technical report. Gestión del Riesgo - Manizales. CORPOCALDAS 2014 (in Spanish).

Manizales. 2016a. Municipal plan for disaster risk management (Plan municipal de gestión del riesgo de desastres). http://www. gestiondelriesgomanizales.com/index.php?option=com_con tent $\&$ view $=$ article $\&$ id $=143 \&$ Itemid $=251$. Accessed 23 Oct 2016 (in Spanish).

Manizales. 2016b. Municipal strategy for emergency response (Estrategia municipal de respuesta a emergencias). http:// www.gestiondelriesgomanizales.com/index.php?option=com content $\&$ view $=$ article $\& i d=144 \&$ Itemid $=253$. Accessed 23 Oct 2016 (in Spanish).

Manizales. Department of Planning. 2017. Territorial ordering plan (Plan de ordenamiento territorial). http://www.manizales.gov. co/Contenido/Alcaldia/86/plan-de-ordenamiento-territorial-vig ente. Accessed 20 Jun 2017 (in Spanish).

Marulanda, M.C. 2013. Probabilistic modelling of earthquake economic losses for the estimation of the fiscal vulnerability and financial risk management (Modelación probabilista de pérdidas económicas por sismo para la estimación de la vulnerabilidad fiscal del estado y la gestión financiera del riesgo). Doctoral thesis. Universidad Politécnica de Cataluña, Barcelona, Spain (in Spanish).

Marulanda, M.C., O.D. Cardona, and A.H. Barbat. 2008. The economic and social effects of small disasters: Revision of the local disaster index and the case study of Colombia. In Megacities: Resilience and social vulnerability, ed. H.G. Bohle, and K. Warner, 110-115. Bonn: United Nations University Environment and Human Security (EHS) and Munich: Re Foundation.

Marulanda, M.C., O.D. Cardona, and A.H. Barbat. 2010. Revealing the socioeconomic impact of small disasters in Colombia using the DesInventar database. Disasters 34(2): 552-570.

Marulanda, M.C., O.D. Cardona, and A.H. Barbat. 2011. Revealing the impact of small disasters to the economic and social development. In Coping with global environmental change, disasters and security - threats, challenges, vulnerabilities and risks, ed. H.G. Brauch, U. Oswald Spring, C. Mesjasz, J. Grin, P. Kameri-Mbote, B. Chourou, P. Dunay, and J. Birkmann, 575-584. Berlin and New York: Springer.

Marulanda, M.C., O.D. Cardona, M.G. Mora, and A.H. Barbat. 2014. Design and implementation of a voluntary collective earthquake insurance policy to cover low-income homeowners in a developing country. Natural Hazards 74(3): 2071-2088.

Marulanda, M.C., O.D. Cardona, M.G. Mora, and D.M. Gonzalez. 2016. Seismic risk assessment for risk transfer: The voluntary collective insurance in Manizales, Colombia. Proceedings of international conference on urban risks, ICUR2016, 30 June-2 July 2016, Lisbon. 
Marulanda, M.C., M.L. Carreño, O.D. Cardona, M. Ordaz, and A.H. Barbat. 2013. Probabilistic earthquake risk assessment using CAPRA: Application to the city of Barcelona, Spain. Natural Hazards 69(1): 59-84.

MAVDT (Ministerio de Ambiente Vivienda y Desarrollo Territorial de Colombia). 2010. Colombian earthquake resistant building code NSR-10 (Reglamento Colombiano de Construcción Sismo Resistente NSR-10) (in Spanish).

Newmark, N. 1965. Effects of earthquakes on dams and embankments. Geotechnique 15(2): 139-160.

Ordaz, M. 2000. Methodology for the seismic risk assessment oriented toward earthquake insurance management (Metodología para la evaluación del riesgo sísmico enfocada a la gerencia de seguros por terremoto). Universidad Nacional Autónoma de México. Mexico City, Mexico (in Spanish).

Ordaz, M. 2014. A simple probabilistic model to combine losses arising from the simultaneous occurrence of several hazards. Natural Hazards 76(1): 389-396.

Ordaz, M., F. Martinelli, V. D'Amico, and C. Meletti. 2013. CRISIS2008: A flexible tool to perform probabilistic seismic hazard assessment. Seismological Research Letters 84(3): 495-504.

Salgado-Gálvez, M.A., G.A. Bernal, and O.D. Cardona. 2016a. Probabilistic seismic hazard assessment of Colombia with updating purposes of the Earthquake-Resistant Building Code for Bridges CCP-14 (Evaluación probabilista de la amenaza sísmica de Colombia con fines de actualización de la Norma Colombia de Diseño de Puentes CCP-14). Revista Internacional de Métodos Numéricos para Cálculo y Diseño en Ingeniería 32(4): 230-239 (in Spanish).

Salgado-Gálvez, M.A., G.A. Bernal, D. Zuloaga, M.C. Marulanda, O.D. Cardona, and S. Henao. 2017a. Probabilistic seismic risk assessment in Manizales, Colombia: Quantifying losses for insurance purposes. International Journal of Disaster Risk Science 8(3). doi:10.1007/s13753-017-0137-6.

Salgado-Gálvez, M.A., M.L. Carreño, A.H. Barbat, and O.D. Cardona. 2016b. Probabilistic seismic risk assessment of Lorca through scenario simulations (Evaluación probabilista del riesgo sísmico en Lorca mediante simulaciones de escenarios). Revista Internacional de Métodos Numéricos para Cálculo y Diseño en Ingeniería 32(2): 70-78 (in Spanish).

Salgado-Gálvez, M.A., D. Zuloaga-Romero, G.A. Bernal, M.G. Mora, and O.D. Cardona. 2014. Fully probabilistic seismic risk assessment considering local site effects for the portfolio of buildings in Medellín, Colombia. Bulletin of Earthquake Engineering 12(2): 671-695.

Salgado-Gálvez, M.A., D. Zuloaga, S. Henao, G.A. Bernal, and O.D. Cardona. 2017b. Probabilistic assessment of annual repair rates in pipelines and of direct economic losses in water and sewage networks: Application to Manizales, Colombia. Natural Hazards. doi:10.1007/s11069-017-2987-z.

Salgado-Gálvez, M.A., D. Zuloaga Romero, C.A. Velásquez, M.L. Carreño, O.D. Cardona, and A.H. Barbat. 2016c. Urban seismic risk index for Medellín, Colombia, based on probabilistic loss and casualties estimations. Natural Hazards 80(3): 1995-2012.

Velasquez, C.A. 2015. Native application for Android smartphones for the evaluation of building damage after an earthquake (Aplicación nativa para teléfonos inteligentes Android para la Evaluación del daño en edificaciones después de un sismo). Technical report. Gestión del Riesgo - Manizales. CORPOCALDAS 2015 (in Spanish).

Velásquez, C.A., O.D. Cardona, M.L Carreño, and A.H. Barbat. 2014. Retrospective assessment of risk from natural hazards. International Journal of Disaster Risk Reduction 10(B): 477-489. 